\title{
Inheritance and Protection of National Sports in Lancang River Basin under the Background of New Rural Construction
}

\author{
Shaochang Yang $^{1}$, Changjiang $\mathrm{Yi}^{1}$ \\ ${ }^{1}$ Baoshan University, Baoshan, 678000, China
}

Keywords: new rural areas; sports of minority nations; inheritance; protection

\begin{abstract}
. with the continuous deepening of the construction of socialist new rural areas, the traditional sports of the minority nations have also been further developed, with increasingly outstanding role in enhancing the condensation of the Chinese nation, carrying forward the national spirit, improving the economic benefit of the society, and strengthening the people's physique. On the background of the new rural construction, this paper is to give advices and suggestions and make modest means to the inheritance and protection of traditional sports culture of the minority nations in the Lancang River basin.
\end{abstract}

\section{Basic profile of sports of minority nations in Lancang River basin}

In the Lancang River basin of China more than 40 minority nations, mainly including Yi, Bai, Naxi, Pumi, Deang, Wa, Zhuang, Yao, Miao, Dai, Tibet and Hui etc., and there are also as many as more than 200 national sports events, like archery, blowgun, spinning top, horse racing, double crutches, wrestling, reed-pipe jumping, bamboo pole jumping, swing, martial arts, dragon boat, tug-of-war, bull fight, flower drum, flower package throwing and billhook dance ${ }^{[1]}$. There are also some sports for self-entertainment within the minority nations not developed, which are used in some special places or festivals, or are for entertainment purely. These sports developed for the demand of survival and labor had been gradually separated from the labor in the long-time development and change and through some reconstruction, they had become special sports at people's leisure, and it is under certain natural environment and social background that the traditional sports of some minority nations were gradually generated. There is no definite provision in the domestic sports field and national and customs science field for the concept of traditional sports of the minority nations.

\section{Connotation of construction of traditional sports culture of the minority nations under the background of new rural construction}

China is a multinational country, and each nation has formed its own traditional sports with characteristics according to its customs habits, regional characteristics and value standard etc. in the process of its development and change. The traditional sports of the minority nations are the comprehensive reflection of our national culture, and each nation has its own unique sports events and rules, and this forms the unique sports form of each nation, and each nation forms its unique sports culture.

The traditional sports culture of the minority nations means the original culture, even blended with other cultures of the minority nations of China in the long national development process, and there has been a significant mutual blending of cultural transformation and national culture, with a long history and reflected in the form of sports. The traditional national sports events are mainly to pursue physical health and mental health, and these are people's independent activities, being some subjective behaviors of people of the minority nations. Under the background of construction of socialist new rural areas, the objective is to cultivate new farmers appropriate for the development and change of society, strengthen the rapid development of rural cultural construction, carry out some cultural activities, so that the farmers can widely participate and enjoy the pleasure brought by the national sports culture. To make great efforts to develop the rural culture, we need to explore some long-term mechanism of rural cultural construction and continuously expand the new approaches of rural cultural construction. The traditional national sports culture is an important part of the rural culture, and plays a very important role in the new rural construction, so it is required to 
emphasize the inheritance and protection of the traditional sports culture ${ }^{[2]}$. Meanwhile, the construction of new rural areas can also provide a greater space and many favorable conditions for the inheritance and development of traditional sports culture of the minority nations.

\section{Relation between new rural construction and traditional sports of minority nations in Lancang River basin}

The new rural construction provides conditions for the development of traditional sports of minority nations in Lancang River basin

Lancang River has a very wide basin, where many minority nations live. With the advantages of special geographical position, attraction of national culture and compatibility of various cultures, this place becomes the cradle of the Chinese culture. The advantageous geographical position and natural sceneries and various customs and practices in Lancang River breed the unique traditional national sports events here, like wrestling, horse racing, bamboo pole jumping, martial arts and archery. Here, different nations have their own characteristics, including the competitive and entertaining traditional folk sports events, which are mainly from the rural areas, being a part of people's production and life, with relatively wide popularization, low requirements and are easily to carry out. Rural area is also a factory to cultivate the modern competitive sports. Throughout the process of world sports history, many globally popular sports events were evolved from the traditional national sports events at the very beginning; the currently popular sports culture were popular in a very few regions or nations at the very beginning, and finally developed into the world common wealth. The new rural construction provides a good condition for the development of traditional sports of minority nations in the rural areas ${ }^{[3]}$.

The new rural construction greatly supports the development of traditional sports of minority nations in Lancang River basin

The main purpose of new rural construction is to cultivate a new generation of farmers under the background of the new times, so that they will have higher quality to accelerate the construction of the new rural areas. The traditional sports events can create a better life for people and make them own good health. However, in some regions in the Lancang River basin, due to mountainous area, the economic development is greatly limited, the economy in some regions is relatively backward, and the public sports facilities also cannot meet people's demand. In such a situation, people will not rely on the sports facilities, which will limit the development of rural sports in a great extent. However, for living and survival, people do not only have to fight against the severe natural environment, but also defeat the enemy surrounding the villages. therefore, people of minority nations living here must have strong health and the power to defeat the nature and enemy. In this way, the shooting and wrestling sports events like archery, and crossbow shooting had been gradually generated. In such a living condition, the traditional sports events in Lancang River basin no not require higher funds and equipment, the sports events can be seen everywhere, without a fixed place, so it is easier to attract a lot of villagers to participate. Due to undeveloped economy in the rural area and the limitation of geographical environment and traffic condition in the minority regions, there is no condition and money to take the vehicles, horse becomes the main production and traffic tool of people. Therefore, the horse racing and skills have also gradually become part of people's life. Other traditional sports of minority nations like horse racing, wrestling, archery, zip-line and pole climbing are developed faster, and the residents can exercise, both economical and beneficial. Undoubtedly, under the background of new rural construction, the state will provide better conditions to bring better opportunities for the development of traditional sports of the minority nations.

New rural construction increases vitality fro the development of traditional sports of minority nations

The new rural construction increases a lot of vitalities to the development of traditional sports of the minority nations in Lancang River, and the sports events of minority nations with national characteristics have a great economic vitality. Depending on these traditional national sports events, people can develop the local tourism. During the development of tourism, the performance industry of national sports events has also been developed accordingly, which will have significance both at home and abroad while attracting the domestic and foreign tourists for visiting, and also bringing 
higher return to the nations in the Langcang River so that more people will know about the traditional national sports. The traditional sports of the minority nations have an important role to improve the villagers' awareness and enhance the national condensation. The sports culture should be rooted in people's mind, making people form a consciousness and participate in the sports activity consciously. As people emphasize health more and more, it is inevitable to participate in the sports events. Most of the people of minority nations live in the deep mountains with closed traffic, leading a pastoral life of land cultivation and weaving for thousands of years. During the slack season, they made some tools to participate in the self-entertainment sports. Gradually, these sports events have been gradually improved and integrated, becoming the relatively regulated traditional national sports events we see today. While participating in the sports events, people can communicate with others happily, and also eliminate some trouble in life, so many villagers love to participate in these sports events. While enjoying life in the traditional culture, the villagers can also feel the charm of national sports events actively.

\section{Effective measures for inheritance and protection of traditional national sports in Lancang River basin}

\section{Establish mechanism for inheritance and development of traditional sports culture of minority nations}

The traditional sports events of the minority nations have experienced the change for thousands of years, but they are still preserved till now. Except some external help, fundamentally, it is because they have self-protection mechanism and can be inherited and developed automatically. To be developed better, the traditional national sports in Langcang River have been effectively protected and inherited, it is because of efficient protection and inheritance that that the traditional sports of the minority nations developed unprecedentedly. With the continuous increasing of the process of sports globalization, the traditional sports of the minority nations have also been shocked from various directions. Many traditional sports events will meet a lot of troubles in the complex environment, and even face the danger of being lost. Aimed at this situation, we need to strengthen the inheritance of sports culture of the minority nations, establish a good protection mechanism and provide a good condition for the tradition of national culture, in this way, we can provide better protection fro the inheritance and development of the traditional sports of the minority nations.

\section{Government strengthens support to the national sports}

As an important part of development of the Chinese minority nations, the traditional sports of the minority nations should also be emphasized sufficiently, the state and government should strengthen support. At present, the development of economy and society has seriously restricted the development of national sports, how to take effective measures to solve this problem needs the government to strengthen support to each minority nation, continuously strengthen the construction of infrastructures in the minority nations, promote the industrial structure adjustment in the minority nations, strengthen education input in the minority areas, establish traditional national sports base, actively develop the minority culture an promote the rapid development of tourism in the minority areas. Now, in order to protect the traditional culture and heritage, the government have take measures to protect the intangible heritages, and the state determines to provide some subsidy to the successors. It is also possible to copy this practice in protection and inheritance of tradition of the minority nations in Lancang River basin, establish more stimulation measures, so that more people will inherit and protect the traditional sports of the minority nations.

Promote the sustainable development of traditional sports events with the development of tourism

The Lancang river basin has quite beautiful sceneries, with very rich resources, these advantageous natural conditions can promote the development of the local tourism. Today, the science and technology are developed rapidly, with the continuous improvement of production level and life quality, people have more spare time relatively, and they have had higher and higher requirements for fitness, entertainment and social communication; as the urban industrialization is developed rapidly, the environmental protection cannot well coordinate with the environmental control, causing continuous deterioration of urban environment, with noise, polluted air, crowded road and together with the increasing work pressure, many people living in cities are thirst to search 
for the quietness of the nature, find out the feel of returning to innocence and explore unique customs. The traditional sports carried out by the patriots of the minority nations living in the deep mountains have been accumulated and deposited for thousands of years, condense the local production and labor mode, life habit characteristics, religious sacrifice and many other expression forms, being the essence and upgrading of the local national culture, with strong appreciation and participation interaction, and can meet people's many demands in leisure, entertainment, fitness and curiosity. The implementation of traditional national culture does not play a good role to the inheritance of the national culture, enrich people's spare life, but also brings considerable economic income and improve the living standards of the local people. Now the traditional national sports have become one of the leading tourism projects of many tourism companies, an the implementation of traditional national sports has been directly associated with the development of tourism. According to the incomplete statistics, in more than 700 successful performances of Yunnan impression, tens of millions of audiences have been attracted, with ticket income exceeding RMB 80 million.

In the minority area of Lancang River basin, people use the geographical advantages to develop the tourism. With the gradual recovery of tourism, many regions have made great efforts to develop tourism. Aimed at people's demands, many regions have started to use their own resources to attract tourists for sightseeing, and launch a series of distinctive characteristics of folk tourism, including the characteristics of many traditional sports of minority nations, in this way, the more tourists will be attracted. For example, during the Torch Festival of the Yi Nation, Yi New Year, "May Day" and National Day Golden Week, make the tourists participate in the traditional sports events of the Yi Nation, feel and perceive the sports culture with Yi characteristics and common psychological characteristics. For example, the horse racing, bull fighting and sheep fighting can make the tourists enjoy the happiness of appreciation, swinging makes the tourist experience the joy of participation. This modern means is the best approach to promote the sustainable development of the traditional sports of the Yi Nation ${ }^{[5]}$. In this way, the tourists will experience the charm in the traditional national sports, feel the traditional culture of the minority nations and promote the inheritance and protection of the sports culture of minority nations.

\section{Summary}

The traditional national sports are an expression form of the national culture, which can reflect the culture and spirit of a nation. The traditional sports of minority nations in Lancang River basin are an important intangible cultural heritage. Therefore, we should continuously strengthen the awareness of inheriting and protecting the traditional sports of the minority nations, fully realize the importance to inherit the traditional sports of minority nations, cherish and respect the spiritual wealth left by the ancestors. Under the background of new rural construction, the minority nations in Lancang River basin should use scientific method to promote the inheritance and protection of the traditional sports of minority nations in combination with the local resources.

\section{References}

[1] Feng Dan, Research on Inheritance and Development of Traditional Sports of Minority Nations in Guizhou [J], Contemporary Sports Technology, 2012, (25):31-32

[2] Zhao Tiantian, Discussion on Inheritance and Protection of Traditional Sports in National Regions of Northeast China [J], Heilongjiang National Periodicals, 2014, (01): 27-28.

[3] Chen Jiaming, Research on Status and Measures of Minority Sports in Sichuan [J], Beautiful Poem, 2011, (33): 23-25

[4] Li Tengda, Discussion on Inheritance and Development of Minority Sports [J], Journal of Jiangxi Institute of Education, 2010, (03): 57-58

[5] Yang Shaochang, Hu Jun, Yi Changjiang, An Linji, Research on Traditional Competitive Entertainment Culture of Yi Nation in Lancang River Basin [J], Journal of Baoshan University, 2011, (06): 59-63 